\title{
Correction to: Asymmetric RF MEMS resonant switch for high speed switching applications
}

\author{
Sara Rizehbandi ${ }^{1}$ Midia Reshadi ${ }^{2} \cdot$ Masoud Baghelani $^{3} \cdot$ Ahmad Khademzadeh $^{1,4}$
}

Published online: 13 October 2018

(C) Springer-Verlag GmbH Germany, part of Springer Nature 2018

\section{Correction to: Microsystem Technologies https://doi.org/10.1007/s00542-018-3859-5}

Unfortunately, the affiliation details of the authors have been published incorrectly. The correct details are given below.

\section{Sara Rizehbandi}

Department of Electrical Engineering, Science and Research Branch, Islamic Azad University, Tehran, Iran

\section{Midia Reshadi}

Department of Computer Engineering, Science and Research Branch, Islamic Azad University, Tehran, Iran

The original article can be found online at https:// doi.org/10.1007/s00542-018-3859-5.

Ahmad Khademzadeh zadeh@itrc.ac.ir

1 Department of Electrical Engineering, Science and Research Branch, Islamic Azad University, Tehran, Iran

2 Department of Computer Engineering, Science and Research Branch, Islamic Azad University, Tehran, Iran

3 Microsystems and Advanced Instrumentation Lab. (MAILab.), Engineering School, Ilam University, Ilam, Iran

4 Research Institute for Information and Communication Technology, Tehran, Iran 